\title{
PROTEÇÃO AMBIENTAL E PLANEJAMENTO ESTATAL: PROGRAMAS E METAS DO PLANO PLURIANUAL FEDERAL 2016 A 2019 PARA A IMPLANTAÇÃO DAS UNIDADES DE CONSERVAÇÃO
}

\section{Giovani Clark ${ }^{1}$ \\ Marcelo Tobias da Silva Azevedo}

\begin{abstract}
Resumo: As unidades de conservação são espaços territoriais especialmente protegidos que possuem como objetivo a preservação de características naturais relevantes. A Lei ${ }^{0}$ 9.985/2000 impõe três elementos mínimos para a adequada gestão da unidade de conservação, ou seja, regularização fundiária, o Plano de Manejo e os Conselhos Gestores. O artigo objetiva estudar as metas e ações do atual Plano Plurianual federal na efetivação dos desígnios constitucionais de definição de espaços territoriais especialmente protegidos e a defesa do meio ambiente ecologicamente equilibrado para as presentes e futuras gerações, inclusive por parte do Estado. A pesquisa é documental, baseada em uma revisão bibliográfica.
\end{abstract}

Palavras-chave: Planejamento; Unidades de Conservação da Natureza; Plano de Manejo; Regularização fundiária; Conselhos Gestores; Plano Plurianual.

\section{ENVIRONMENTAL PROTECTION AND STATE PLANNING: PROGRAMS AND GOALS OF THE MULTI-YEAR PLAN 2016 TO 2019 FOR FEDERAL IMPLEMENTATION OF CONSERVATION UNITS}

\begin{abstract}
Protected Areas are specially protected territorial spaces whose purpose is the preservation of relevant natural characteristics. Law 9.985 / 2000 imposes three minimum elements for the proper management of the conservation unit, that is, expropriation, the Management Plan and the Management Councils. The objective of this article is to study the goals and actions of the current brazilian Economic Planning in the realization of the constitutional purposes of defining specially protected territorial spaces and ecologically balanced environmental protection for the present and future generations, including by the State. This research is documentary, based on a bibliographical review.
\end{abstract}

Key-words. Planning; Protected Areas; Management Plan; Expropriation; Management Councils; Economic Planning.

\footnotetext{
${ }^{1}$ É doutor em Direito Econômico/UFMG, Professor da Programa de Pós-graduação da PUC Minas e docente da Faculdade de Direito da UFMG.

${ }^{2}$ Discente do programa de Pós-Graduação em sentido estrito - Mestrado, da Pontifícia Universidade Católica de Minas Gerais. Especialista em Gestão do Ambiente e Sustentabilidade pela Fundação Getúlio Vargas. Bacharel em Direito pela Universidade Federal de Minas Gerais.
}

Rev. de Direito, Economia e Desenvolvimento Sustentável| e-ISSN: 2526-0057| Maranhão | v. 3 | n. 2 | p. 61 - 81 Jul/Dez. 2017. 


\section{INTRODUÇÃO}

As unidades de conservação são espaços territoriais especialmente protegidos que possuem como objetivo a preservação de características naturais relevantes. Integra amplo rol de instrumentos e ações que o Estado possui para cumprir o desígnio constitucional de defesa e proteção do meio ambiente ecologicamente equilibrado para as presentes e futuras gerações.

O regulamento das áreas protegidas está prevista na Lei Federal nº. 9.985/2000, conhecida como a Lei do Sistema Nacional de Unidades de Conservação (SNUC). A definição dessas áreas decorre de ato de Poder Público, que além de instituí-las é responsável pelo seu gerenciamento.

As ações para implementação e manutenção da área protegida depende de recursos públicos. A citada Lei Federal no . 9.985/2000 prevê a possibilidade de se exigir do empreendedor responsável por atividades considerados de significativo impacto ambiental o pagamento de uma parcela dos investimentos a serem dispendidos para a instalação do empreendimento sujeito ao licenciamento ambiental. O pagamento é entendido como uma forma de compartilhamento das despesas ${ }^{3}$ para custear a implantação de unidades de conservação de proteção integral, atendido o princípio do usuário-pagador. Contudo, a experiência de dezessete anos de vigência da Lei, cuja constitucionalidade esteve em discussão no Supremo Tribunal Federal ao longo desses anos, demonstra que os recursos são insuficientes.

Em razão da escassez de recursos financeiros, os custos decorrentes da implantação e manutenção das unidades precisam ser destinados pelo Executivo, que, diante dos demais anseios sociais, adota o planejamento, inclusive fixado em vários comandos da constituição de 1988, como forma de racionalizar os meios disponíveis para se atingir os melhores resultados possíveis

$\mathrm{O}$ artigo objetiva estudar as metas e ações do planejamento da União, mais especialmente do atual Plano Plurianual 2016 a 2019, para atender os objetivos constitucionais de defesa e proteção do meio ambiente ecologicamente equilibrado, especialmente no que se refere a definição de espaços territoriais especialmente protegidos. A pesquisa é documental,

\footnotetext{
${ }^{3}$ Entendimento fixado pelo Supremo Tribunal Federal, na Ação Direta de Inconstitucionalidade n. 3.378, da Relatoria de Carlos Ayres Brito.
}

Rev. de Direito, Economia e Desenvolvimento Sustentável| e-ISSN: 2526-0057| Maranhão | v. 3 | n. 2 | p. 61 - 81 | Jul/Dez. 2017. 
baseado e, uma revisão bibliográfica e possui como referenciais teóricos os doutrinadores de Direito Ambiental e o introdutor do Direito Econômico no Brasil, Prof. Washington Peluso Albino de Souza.

\section{AS UNIDADES DE CONSERVAÇÃO DA NATUREZA: CONCEITO, FUNDAMENTOS E NATUREZA JURÍDICA}

A Constituição de 1988 designou ao Estado a obrigação de definir no território nacional espaços territoriais e seus componentes a serem especialmente protegidos, conforme artigo 225, §1, III. A criação dos espaços não se limita às unidades de conservação, podendo ser enquadradas nesse espectro vários outros instrumentos da legislação ordinária, como as áreas de preservação permanente (APPs) descritas no Código Florestal (Lei nº 12.651/2012).

Contudo, são as unidades de conservação que melhor ilustram o desígnio da Lei Maior, sendo comumente classificada pelos teóricos nacionais como espaço territorial especialmente protegido em sentido estrito. Édis Milaré (2013) defende que "no conceito de espaços territoriais especialmente protegidos, em sentido estrito, tal qual enunciado na Constituição Federal, se subsumem apenas as unidades de conservação típicas” (MILARÉ, 2013, p. 183), complementando que constituíram a categorização desses espaços em sentido amplo as demais áreas protegidas.

O texto constitucional indica que a proteção ambiental perseguida ultrapassa a simples definição de espaços do território para alcançar os componentes integrantes dos espaços, como justificativa para a sua preservação. É justamente esses componentes que motivam a designação dos espaços como protegidos e, assim, determinam que o uso e fruição da propriedade privada estará sujeita a regras específicas que considerem a necessidade de conservação de seus atributos. Na opinião de Celso Fiorillo e Marcelo Abelha:

Estes espaços territoriais especialmente protegidos podem ser em áreas geográficas públicas ou privadas, que justamente por serem dotados de atributos ambientais, merecem um tratamento diferenciado e especializado. Em sendo declarado desta natureza, então sujeitar-se-á a um regime jurídico de interesse público, inclusive no tocante à propriedade, se a situação exigir (FIORILLO; RODRIGUES, 1999, p. 195).

O regime jurídico público dos espaços territoriais especialmente protegidos se divide. Possui conotação diferente para os espaços em sentido amplo (APPs,e outros) e para os espaços 
em sentido estrito (unidades de conservação). Para o primeiro, a proteção constitucional tem um sentido de perenidade, intocabilidade, traduzida pela expressão preservação; enquanto, para o segundo, o sentido é de utilização racional e sustentável, visando a manutenção, sendo que o legislador traduziu com a expressão conservação.

$\mathrm{O}$ atual Ministro do Superior Tribunal de Justiça, Herman Benjamim, ao estudar as unidades de conservação instituídas pela Lei $n^{\circ}$. 9.985/2000, explica que a opção do texto constitucional por tratar como espaços territoriais possui a acepção científica adequada, respeitando "o standard científico apropriado, segundo o qual 'conservação' não é gênero, muito menos gênero do qual 'preservação' seria espécie” (BENJAMIM, 2001, p. 36). Considerando tal premissa, conservação e preservação seriam as espécies de proteção especial (gênero) encontrada no texto constitucional (BENJAMIM, 2001, p. 36).

Com isso tem-se que as áreas de preservação permanente se sujeitam ao regime de direito público de garantia integral, traduzindo a ideia de impossibilidade de exploração econômica, admitidas exceções temporárias em caso do exercício de atividades de utilidade pública previstas em lei; enquanto as unidades de conservação, ainda que tenha características protetivas que restrinjam o uso livre da propriedade privada, seriam enquadradas como áreas sujeitas ao manejo público, permitindo-se, em casos muitos específicos, a coexistência permanente entre proteção especial e utilização racional da propriedade. Alias, é a opinião de Nicolao Dino de Castro e Costa Neto:

\footnotetext{
$\mathrm{Na}$ acepção comum, os termos conservação e preservação se equivalem. No campo do Direito Ambiental, contudo, tem-se buscado estabelecer uma distinção, reservando-se para a segunda expressão um sentido mais rígido de proteção. Assim, enquanto regime de preservação permanente pressupõe a "manutenção da integralidade e perenidade dos recursos ambientais", sem a possibilidade de exploração econômica direta, o regime de conservação pressupõe utilização racional, manejo" (COSTA NETO, 2003, p. 203).
}

A natureza jurídica das unidades de conservação é confirmada pela lei que as regulamenta e cria do Sistema Nacional de Unidades de Conservação (SNUC), Lei Federal nº. 9.985/2000. No conceito legal, unidade de conservação significa o espaço territorial e seus recursos ambientais, incluindo as águas jurisdicionais, com características naturais relevantes, legalmente instituído pelo Poder Público, com objetivos de conservação e limites definidos, sob regime especial de administração, ao qual se aplicam garantias adequadas de proteção (art. $2^{\circ}$, 
I, da Lei n. 9.985/2000). O dito conceito legal pode ser detalhado em três aspectos essenciais, reafirmando a natureza jurídica dos espaços especiais.

O primeiro aspecto, contido na expressão "o espaço territorial e seus recursos ambientais, incluindo as águas jurisdicionais, com características naturais relevantes" (art. $2^{\circ}$, I, da Lei n. 9.985/2000), refirma a integração do espaço pelos seus atributos relevantes, incluindo os "recursos ambientais" no próprio termo unidade de conservação, inclusive as águas jurisdicionais, que integram o espaço protegido. Esse aspecto revela que a unidade de conservação não pode ser criada sem o atributo especial que a justifique, bem como a existência das limitações administrativas a serem impostas à propriedade privada e a livre iniciativa são resultantes da necessidade de manutenção das características especiais.

Adiante, o mesmo art. $2^{\circ}$, I, da Lei Federal trata sobre o fato da unidade de conservação ser "legalmente instituído pelo Poder Público, com objetivos de conservação e limites definidos", revelando o seu segundo aspecto.

A exigência de ato legalmente instituído possui duas consequências. A primeira é a necessidade da existência da edição de ato formal de criação, não se reconhecendo as restrições impostas pela unidade de conservação apenas pela existência dos aspectos naturais relevantes, sem o ato que reconheça a sua proteção. A instituição das unidades de conservação diferenciase, assim, das áreas de preservação permanente, para as quais basta que a situação do local físico tenha as características descritas no Código Florestal (e.g. margem dos cursos d'água). Para as unidades de conservação, portanto, é necessária a cumulação entre a característica natural relevante e o ato de criação da unidade, que reconheça a necessidade de proteção.

A segunda consequência é que o ato de criação está sujeito a regras próprias de gênese, descritas na Lei do SNUC, sendo que o desrespeito a essas normas sujeita o ato de criação à invalidade jurídica, podendo ser reconhecida pela Administração Pública, de ofício, no exercício da autotutela administrativa ou, como qualquer ato de Poder Público, sujeito a apreciação judicial e declaração da sua nulidade.

Nesse mesmo trecho do conceito pode-se ainda indicar que a Lei do SNUC é ampla ao determinar a possibilidade de ato do "Poder Público". A criação de unidade de conservação, estabelecendo limitações administrativas ao território, com a geração de custos para sua implantação como para sua manutenção a serem custeadas pelo Estado, é típica atividade administrativa reservada à função Executiva, que se manifesta por meio de atos administrativos. 
Contudo, a dúvida que ressai da leitura do artigo é a possibilidade da criação das unidades de conservação serem efetivadas, não apenas os decretos, mas por outros atos do Poder Público, decorrentes do exercício das funções Legislativa e Jurisdicionais, especificamente leis e sentenças. Herman Benjamim opina que atuação dessas funções decorrem do poder-dever de salvaguardar a natureza e explica:

No caso do Judiciário, na esteira do posicionamento jurisprudencial em matéria de tombamento, a sua atuação concreta independe de prévia manifestação da administração pública no caso concreto, estabelecendo unidade de conservação específica. O juiz, aqui, age exatamente para suprir a omissão descabida, ou a intervenção insuficiente, do Poder Público. (BENJAMIM, 2001, p. 303)

Por fim, ainda nesse segundo aspecto do conceito legal, encontra-se a indicação de objetivos e limites definidos. $\mathrm{O}$ ato de criação da unidade de conservação deve prever essas duas características. Apenas se enquadra na modalidade unidade de conservação àquele espaço cujos limites estejam claramente definidos, excluindo-se do conceito outras formas de proteção ambiental encontrada em leis diversas, cuja forma de proteção baseia-se apenas na caraterística ambiental relevante e não pela sua delimitação no território.

Da mesma forma, há a necessidade de se motivar o objetivo da instituição da proteção naqueles limites, indicando-se, no mínimo, a existência da característica natural relevante que se pretende proteger especialmente naquela porção do território, uma vez que, é essencial a própria unidade de conservação a existência dessa característica ambiental relevante.

O terceiro aspecto não representa dificuldades ao intérprete, superado o entendimento dos aspectos antecedentes. Sobre a área delimitada da unidade de conservação com objetivos de preservação definidos, ambos determinados em ato do Poder Público, estará sob regime especial de administração, ao qual se aplicam garantias adequadas de proteção.

A propriedade privada passa a atender a função de proteção ambiental, cujos parâmetros protetivos estarão presentes a partir da constituição do ato determinado pelo agente público responsável pela sua administração. A proteção especial é pautada pelo fim que justificou a sua criação, mas com a afetação de todo o interior da unidade de conservação, devidamente definidas pelos seus limites geográficos. O esvaziamento da livre fruição da propriedade privada estará, então, sujeito à desapropriação pelo Poder Público, ou, caso aquele não ocorra, eventuais limitações administrativas ao uso da propriedade poderão estar sujeitas à reparação civil, devido as regras de responsabilização extracontratual do Estado. 


\subsection{As Modalidades e as Classificações das Unidades de Conservação}

A existência de unidades de conservação precede a Lei Federal n ${ }^{\circ}$. 9.985/2000, instituidora do Sistema Nacional das Unidades de Conservação (SNUC). O primeiro Parque Nacional, do Itatiaia, foi criado em 1937, pelo Decreto $\mathrm{n}^{\circ}$. 1.713. O revogado Código Florestal, Lei Federal no. 4.771/1965, tratava da existência de Parques Nacionais, Reservas Biológicas e Florestas Públicas, modalidades de unidades de conservação posteriormente incorporadas ao sistema. A Lei Federal nº 6.938/1981 tratava de uma modalidade de Estação Ecológica, também inserida posteriormente no SNUC.

Várias outras modalidades foram instituídas pelo Poder Público, sem o vínculo adequado a uma legislação federal que a sustentasse. Várias Áreas de Proteção Ambiental (APA) foram instituídas por todos os entes federados, antes da vigência da Lei do SNUC.

Portanto, a Lei do SNUC não criou as unidades de conservação. A existência das unidades de conservação e sua evolução demonstraram que "a mera delimitação de áreas protegidas não é suficiente, sendo necessária a criação de um verdadeiro sistema de áreas de preservação para que seja garantida a eficiência desta medida" (AZEVEDO; MOREIRA, 2013, p. 407). Assim, a lei reuniu todas as iniciativas esparsas da legislação de espaços territoriais especialmente protegidos e definiu a organização de um sistema coeso, com divisão das unidades de conservação em categorias e o estabelecimento de regras comuns para todas as categorias e as modalidades de unidades.

A Lei do SNUC cataloga doze modalidades de unidades de conservação distribuídas em duas categorias. A primeira categoria é o conjunto de unidades de conservação de proteção integral, constituída pelas unidades Estação Ecológica, Reserva Biológica, Parque Nacional, Monumento Natural e Refúgio de Vida Silvestre. A segunda categoria é o conjunto de unidades de conservação de uso sustentável, integradas pelas unidades Área de Proteção Ambiental, Área de Relevante Interesse Ecológico, Floresta Nacional, Reserva Extrativista, Reserva de Fauna, Reserva de Desenvolvimento Sustentável e Reserva Particular do Patrimônio Natural.

As unidades de conservação de proteção integral possuem como objetivo comum "preservar a natureza, sendo admitido apenas o uso indireto dos seus recursos naturais, com exceção dos casos previstos na Lei” (art. $7^{\circ}, \S 1^{\circ}$, da Lei n. 9.985/2000). Por sua vez, as unidades

Rev. de Direito, Economia e Desenvolvimento Sustentável| e-ISSN: 2526-0057| Maranhão | v. 3 | n. 2 | p. 61 - 81 Jul/Dez. 2017. 
de conservação de uso sustentável possuem como objetivo comum "compatibilizar a conservação da natureza com o uso sustentável de parcela dos seus recursos naturais" (art. $7^{\circ}$, $\S 2^{\circ}$, da Lei n. 9.985/2000).

Permeados por vários conceitos jurídicos indeterminados, a descrição dos objetivos legais permite reconhecer a diferença substancial de grau de intervenção antrópica a partir da instituição de uma das modalidades das unidades. As unidades de proteção integral são identificadas pelo seu caráter preservacionista, sendo que em algumas de suas modalidades permitem-se apenas a realização de pesquisas científicas autorizadas pelos órgãos gestores das unidades. Já as unidades de uso sustentável se caracterizam pela "possível" conciliação entre a proteção da natureza e algum tipo de utilização das propriedades privadas.

\subsection{Processo de Criação, Implantação e Extinção das Unidades de Conservação}

O artigo 22, §2º da Lei Federal nº $.9 .985 / 2000$, impõe que a criação de uma unidade de conservação deva ser "precedida de estudos técnicos e de consulta pública que permitam identificar a localização, a dimensão e os limites mais adequados para a unidade, conforme se dispuser em regulamento". O regulamento citado foi instituído pelo Decreto Federal $n^{\circ}$ 4.340/2002, que, praticamente à sinonímia da norma regulada, estabelece que "compete ao órgão executor proponente de nova unidade de conservação elaborar os estudos técnicos preliminares e realizar, quando for o caso, a consulta pública e os demais procedimentos administrativos necessários à criação da unidade" (art. $4^{\circ}$, do Decreto n. 4.340/2002).

Da leitura de ambos os dispositivos fica claro que a criação de Unidade de Conservação não é ato aleatório, conforme ensinamentos de Herman Benjamin (2004, p. 304). Deve, isso sim, estar embasada em estudos técnicos e em consulta pública. É o estudo técnico que permitirá não só definir os limites, a dimensão e a localização da futura unidade de conservação, como, também, e principalmente, a existência dos pressupostos necessários à sua criação, a categoria e a modalidade da unidade a ser criada.

Existem precedentes judicias que reconhecem a nulidade do ato de criação da Unidade de Conservação quando não precedida de estudos técnicos adequados, como se observa no julgado abaixo de relatoria da Exma. Sra. Maria Isabel Gallotti Rodrigues do Tribunal Regional Federal da $1^{\circ}$ Região:

Rev. de Direito, Economia e Desenvolvimento Sustentável| e-ISSN: 2526-0057| Maranhão | v. 3 | n. 2 | p. 61 - 81 | Jul/Dez. 2017. 


\begin{abstract}
AGRAVO DE INSTRUMENTO. CRIAÇÃO DE UNIDADE DE CONSERVAÇÃO DA NATUREZA DO TIPO RESERVA EXTRATIVISTA (LEI 9.985/2000; DECRETO 4.340/2002). ESTUDOS TÉCNICOS E CONSULTA PÚBLICA. OBSERVÂNCIA. 1. No processo de criação de unidades de conservação da natureza, à vista do disposto no artigo $22, \S \S 2^{\circ}$ e $3^{\circ}$, da Lei $9.985 / 2000$ e nos $\operatorname{artigos~} 4^{\circ}$ e $5^{\circ}$ do Decreto 4.340/2002, a consulta pública à população interessada deve ser precedida dos estudos técnicos que comprovem a viabilidade dela (unidade de conservação). 2. Por sua vez, a consulta pública, além de observar os preceitos legais e regulamentares (Lei 9.985/2000, artigos $5^{\circ}$, III, e 22, $\S \S 2^{\circ}$ e $3^{\circ}$; Decreto $4.340 / 2002$, artigos $4^{\circ}$ e $5^{\circ}$ ), deve ser procedida com obediência ao disposto no Guia de Consultas Públicas para Unidades de Conservação, de forma a permitir a mais ampla divulgação e oportunidade de discussão sobre as implicações da criação da unidade de conservação, em observância ao princípio democrático. 3. Improcedência das alegações de ofensa ao disposto no artigo 43 da Lei 9.985/2000 e de ausência de dotação orçamentária (Lei 4.320/1964, artigo $4^{\circ}$ ). 4. Ocorrência do 'periculum in mora', uma vez que a criação da unidade de conservação em causa sem a observância dos preceitos legais e regulamentares pertinentes poderá implicar dano de difícil reparação à população a ser atingida pelo ato do Poder Público. 5. Agravo de instrumento provido em parte. (AG 2006.01.00.015900-0/BA, Rel. Desembargadora Federal Maria Isabel Gallotti Rodrigues, Conv. Juiz Federal Leão Aparecido Alves (conv.), Sexta Turma, DJ p.53 de 29/01/2007).
\end{abstract}

Adicionalmente, o ato de criação da Unidade de Conservação não pode estar em dissonância do que foi discutido na consulta pública, sob pena de torná-la instrumento completamente inútil e mera formalidade a ser observada pela Administração. Este verdadeiro instrumento democratizante que o legislador inseriu no processo de criação das Unidades de Conservação se tornaria letra morta, fragilizando a democracia participativa instituída pelo texto constitucional, o que não significa exigir a aquiescência dos presentes, tratando-a como uma assembleia deliberativa.

A nossa Corte Superior reconhece a nulidade do ato de instituição de Unidade de Conservação sem a prévia realização de consulta pública. O Supremo Tribunal Federal já teve oportunidade de se pronunciar sobre o assunto no julgamento do Mandado de Segurança ${ }^{\circ}$ 24.184, ocasião em que declarou nulo o ato que ampliou uma Unidade de Conservação sem a prévia realização de genuína consulta pública:

Quando da edição do Decreto de 27.02.2001, a Lei no 9.985/00 não havia sido regulamentada. A sua regulamentação só foi implementada em 22 de agosto de 2002, com a edição do Decreto $n^{\circ} 4.340 / 02$. O processo de criação e ampliação das unidades de conservação deve ser precedido da regulamentação da lei, de estudos técnicos e de consulta pública. O parecer emitido pelo Conselho Consultivo do Parque não pode substituir a consulta exigida na lei. O Conselho não tem poderes para representar a população local. Concedida a segurança, ressalvada a possibilidade da edição de novo 
decreto. (MS 24184, Relator(a): Min. ELLEN GRACIE, Tribunal Pleno, julgado em 13/08/2003, DJ 27-02-2004).

O acórdão do STF deixa claro que a prévia oitiva à população afetada não é mera formalidade. Muito pelo contrário, é requisito indispensável à higidez do ato administrativo.

Por sua vez, o processo de extinção da unidade de conservação não depende da realização de estudos ou consultas, mas estará sujeito ao processo legislativo, conforme prevê a Lei do SNUC. Isso porque a Constituição da República assim exige, ao impor que a alteração e a supressão dos espaços territoriais especialmente protegidos são permitidas somente por meio de lei (art. 225, $\left.\S 1^{\circ}, \mathrm{III}\right)$.

Para Paulo Affonso Leme Machado (2016) o sentido constitucional é mais amplo do que o descrito pela Lei Federal. A supressão prevista no texto constitucional não se limita a desafetação de bem público, que exigiria o apossamento da área. Aquela ocorre mesmo com a unidade que já tenho sido instituída, mas não tenha sido implementada. Ainda, segundo o autor, "não só a diminuição de limites da unidade de conservação necessita de lei específica, como, também, a alteração das finalidades dessa unidade" (MACHADO, 2016, p. 1002).

O ponto mais sensível das unidades de conservação é concernente a sua implantação. A Lei exige para algumas unidades a posse e o domínio público, o que importará na necessidade de desapropriação das propriedades privadas inseridas no interior de seus limites. Para outras modalidades de unidade de conservação não se exigirá o domínio público, podendo ser necessário o apossamento público em eventual incompatibilidade entre o uso das propriedades privadas e a proteção perseguida.

No grupo das unidades de conservação de proteção integral, para a Estação Ecológica, a Reserva Biológica e o Parque Nacional, a lei exige a posse e domínio públicos e determina a desapropriação das propriedades privadas. Para as modalidades Monumento Natural e Refúgio da Vida Silvestre a lei não exige de imediato a desapropriação, podendo existir propriedades privadas no seu interior, desde que seja possível compatibilizar os objetivos da unidade com a utilização da terra e dos recursos naturais do local pelos proprietários.

Mesmo na categoria de unidades de conservação de uso sustentável haverá a imputação ao Poder Público do dever de desapropriar. As Florestas Públicas, as Reservas Extrativista, as Reservas da Fauna e as Reservas de Desenvolvimento Sustentável exigem a posse e domínios públicos.

Rev. de Direito, Economia e Desenvolvimento Sustentável| e-ISSN: 2526-0057| Maranhão | v. 3 | n. 2 | p. 61 - 81 | Jul/Dez. 2017. 
As Áreas de Proteção Ambiental e Área de Relevante Interesse Ecológico podem ser constituídas de propriedades privadas e poderá o Poder Público, respeitado os limites constitucionais, impor restrições para a utilização da propriedade. Isso representa que o Poder Público poderá ainda, considerando critérios de responsabilização extracontratual do Estado, ser obrigado a eventuais indenizações devidas aos particulares. É evidente que, alertam Guilherme José Purvin de Figueiredo e Marcia Dieguez Leuzinger (2001, p. 472), “a função social (...) impõe limites internos ao exercício do direito de propriedade, independentemente da vontade do particular, limites esses que, na maioria das vezes, sequer são indenizáveis".

A implantação das unidades de conservação não se resume ao apossamento realizado pelo Poder Público. Édis Milaré (2013, p. 1.231) reforça que a implantação consiste em tornalas em realidade concreta. Ainda que a implantação seja mais do que a desapropriação determinada pela lei, essa é, indubitavelmente, a ação principal que deva ser tomada pelo Poder Público e precedente a qualquer ato de gestão que seja eficaz. A implantação do espaço protegido exigirá, ainda, a elaboração de Plano de Manejo e manutenção de Conselho Gestor para decidir as ações a serem promovidas pela unidade para atendimento à população.

Mesmo o ato de criação não é isento de custos, visto que recursos financeiros consideráveis devem ser dispendidos para que os estudos sejam adequados para a exigência da lei e para que o Estado tenha ciência adequada dos impactos de suas decisões, bem como para que as consultas públicas sejam efetivas, permitindo a comunicação adequada com a população atingida.

\subsection{Os Dados das Unidades de Conservação Brasileiras}

Em conjunto com a criação do Sistema Nacional de Unidades de Conservação, a Lei Federal $n^{\circ}$. 9.985/2000 determinou a criação do Cadastro Nacional de Unidades de Conservação. O cadastro reúne todos os dados de unidades de conservação da nação, criadas por quaisquer dos entes federados. A responsabilidade pela sua manutenção é do Ministério de Meio Ambiente, que atualiza com os dados fornecidos pelos órgãos estaduais e municipais.

O cadastro possui dados muito relevantes para estudiosos, pesquisadores, além de apoiar o próprio Poder Público na adoção de políticas preservacionistas no território sujeito a 
sua gestão. A última consolidação dos dados foi realizada em agosto de $2016^{4}$. Os dados consolidados ajudam a traçar o panorama adequado da ocupação do território pelas unidades de conservação.

Em agosto de 2016 o CNUC indicava a existência de 2.029 unidades de conservação no Brasil. Do total de unidades de conservação, foram definidas como unidades de conservação de proteção integral o total de 636 unidades e de uso sustentável o total de 1.393 unidades.

As unidades de conservação de proteção integral estaduais são predominantes se consideradas o total de unidades. Os Estados, em conjunto, instituíram 348 unidades de conservação de proteção integral, sendo 61 Estações Ecológicas, 29 Monumentos Naturais, 205 Parques Estaduais, 30 Refúgios da Vida Silvestre e 23 Reservas Biológicas. A União instituiu 146 unidades de proteção integral e os Municípios somados 142 unidades.

A modalidade Parque predomina entre as modalidades de proteção integral, existindo 395 espalhados por todo a nação, sendo 73 Federais, 205 Estaduais e 117 Municipais.

Nas modalidades de uso sustentável predomina a instituição de Áreas de Proteção Ambiental, no total de 302, e Reservas Particulares do Patrimônio Natural, no total de 808.

Nos dados gerais há amplo predomínio das unidades instituídas pela União, com o total de 814 unidades, seguidas pelos Estados 483 e pelos Municípios 96. Entretanto, essa disparidade pode ser justificada pela própria fragilidade do Cadastro, que depende da atualização fornecida voluntariamente pelos poderes locais.

Os dados mais relevantes da consolidação do cadastro são a ocupação em área do território por esses espaços protegidos. O total geral de ocupação do território nacional, incluindo os dados das unidades de conservação instituídas por todos os entes e de todas as modalidades, é a extensão de 1.582.758 quilômetros quadrados. Em comparação, a área total do território nacional é de 8.515.767,049 quilômetros quadrados ${ }^{5}$, isso significa que aproximadamente $17,64 \%$ do território nacional é onerado por unidades de conservação. Em comparação, a área ocupada por unidades de conservação é superior a área do Estado do Amazonas, o maior Estado brasileiro, que possui 1.559.148,890 quilômetros quadrados ${ }^{6}$.

\footnotetext{
4 Dados do CNUC, disponível em: http://www.mma.gov.br/images/arquivo/80112/CNUC_Agosto\%20\%20Categorias_copy.pdf, Acessado em 22/01/2017.

5 Disponível em http://www.ibge.gov.br/home/geociencias/cartografia/default_territ_area.shtm. Acessado em 22/01/2017.

6 Disponível em http://www.ibge.gov.br/home/geociencias/areaterritorial/principal.shtm. Acessado em 22/01/2017.
} 
A área ocupada pelas unidades de conservação de proteção integral corresponde a 541.296 quilômetros quadrados. Excluídas do total dessa área as porções ocupadas pelos Monumentos Naturais e Refúgios da Vida Silvestre, que não possuem a obrigatoriedade legal do domínio da propriedade para o domínio público, tem-se uma área de 536.008 quilômetros quadrados. Considerando a hipótese de não criação de novas unidades de conservação de proteção integral, tal área, que precisaria ser desapropriada pelo Poder Público para efetivar a proteção exigida pela Lei, é levemente superior a área dos Estados de São Paulo e Rio Grande do Sul somadas.

Trata-se de um enorme desafio para a nação. Conforme destacam Marcelo Azevedo e Luísa Moreira, "a extensão da área ocupada pelas Unidades de Conservação e a existência de um sistema não são suficientes para garantir uma proteção efetiva dos ecossistemas brasileiros" (AZEVEDO; MOREIRA, 2013, p. 427). A efetivação da proteção especial exigidas por essas unidades, que reclamam o domínio público, contudo, não se encerra com a expropriação das propriedades privadas. É necessário ainda que as unidades possuam estrutura para o cumprimento de seus objetivos principais, mesmo que tal objeto se restrinja a manutenção integral do recurso ambiental intocado para as futuras gerações.

Os dados indicam confirmam a observação inicial que parte significativa das unidades de conservação existem apenas no ato do Poder Público que as criou e, mesmo as existentes, estão longe de possuir a gestão ambiental adequada, que deveria considerar, no mínimo, o cumprimento a Lei do SNUC.

\subsection{As Dificuldades na Efetivação das Unidades de Conservação}

A efetivação das unidades de conservação importa na execução da proteção especial determinada tanto pela Constituição da República, como pela própria Lei que disciplina o funcionamento do SNUC.

Vários fatores importam na não efetivação de seus objetivos legais. O relato dos órgãos gestores informam sobre a ocorrência de incêndios florestais, sobre invasões e exploração irregulares de recursos naturais, falta de recurso para permitir a manutenção de áreas que poderiam ser visitadas pela população, entre outros problemas corriqueiros. Contudo, não existem pesquisas e dados concretos sobre as inúmeras dificuldades apontadas.

Rev. de Direito, Economia e Desenvolvimento Sustentável| e-ISSN: 2526-0057| Maranhão | v. 3 | n. 2 | p. 61 - 81 Jul/Dez. 2017. 
Por outro lado, entende-se que a busca pela efetivação da proteção especial a ser promovida por tais espaços deve ter como ponto de partida o efetivo cumprimento das exigências legais. As exigências legais podem ser facilmente indicadas e servem como parâmetro para definir a efetividade da implantação das unidades de conservação.

A principal é a desapropriação de áreas no interior das unidades de conservação, para as quais se exigem o domínio público.

Outro desafio para as unidades de conservação é a instituição do Plano de Manejo. A Lei do SNUC o define como "documento técnico mediante o qual, com fundamento nos objetivos gerais de uma unidade de conservação, se estabelece o seu zoneamento e as normas que devem presidir o uso da área e o manejo dos recursos naturais, inclusive a implantação das estruturas físicas necessárias à gestão da unidade" (art. 27, Lei no 9.985/2000).

Por imposição da lei, prevista ainda no art. $27, \S 1^{\circ}$, o Plano de Manejo deve abranger a área da unidade de conservação, sua zona de amortecimento e os corredores ecológicos, incluindo medidas com o fim de promover sua integração à vida econômica e social das comunidades vizinhas. Aquele é o documento essencial para as unidades de conservação. Nele estará traçado o regulamento interno da unidade, determinando as ações positivas e negativas necessárias para cumprimento do seu objetivo específico.

Por fim, as unidades de conservação disporão de Conselhos Gestores, constituídos por representantes dos órgãos públicos e organizações da sociedade civil, sendo presididos pelo órgão responsável pela Administração da unidade.

As três imposições legais (regularização fundiária, Plano de Manejo e Conselhos Gestores) são os elementos mínimos para a adequada gestão da unidade de conservação.

Como os dados demonstram, definitivamente, a carência da nação não passa pela necessidade de se definir e instituir espaços protegidos, sem prejuízo da necessidade de se definir regras e parâmetros especiais para lugares específicos ainda não alcançados pela proteção especial definida na Constituição. Os principais desafios da efetivação do SNUC estão concentrados na efetivação das áreas existentes, que não cumprem nem o mínimo essencial exigido pela legislação.

Para sua implantação há a dependência de recursos financeiros, que precisam ser compartilhados com os demais anseios da sociedade. Definitivamente, apesar da indiscutível importância, não ocupa a posição dos itens prioritários demandados pela população, como 
saúde, educação e segurança. Todavia não podem ser ignorados pelo Poder Público. A responsabilidade exigida na criação de unidades de conservação deve ponderar a necessidade futura de recursos para sua efetivação.

\section{O PLANEJAMENTO ESTATAL E AS UNIDADES DE CONSERVAÇÃO}

Segundo o Professor Washington Peluso Albino de Souza (2017, p. 372), o Planejamento consiste no ato de planejar. O conceito está intimamente associado a ideia da escassez dos recursos disponíveis e a adoção da decisão que permita o melhor aproveitamento destes. Para Souza (2017) o conceito "prende-se essencialmente à ideia de racionalizar o emprego dos meios disponíveis para deles retirar os efeitos mais favoráveis" (SOUZA, 2017, p. 372). Segundo ele, ainda, é ato político de efetivação da intervenção do Estado na economia.

Igualmente defendendo o planejamento como uma técnica de intervenção estatal indireta, Giovani Clark e Gustavo Vidigal Costa indicam que "cabe assim ao Estado brasileiro um papel de protagonista social, agindo planejadamente, sempre voltado ao desenvolvimento sustentável e tendo o mercado interno como patrimônio nacional" (CLARK; COSTA, 2015, p. 107). Em síntese os autores indicam o conceito de planejamento que se adota neste estudo:

\footnotetext{
O planejamento estatal corresponde (1) à reunião de esforços políticos, econômicosfinanceiros e jurídicos, (2) objetiva coordenar os recursos orçamentários disponíveis, (3) aplicando-os (recursos orçamentários) a metas específicas, (4) em tempo e modo previamente prescritos, (5) na busca da linha de maior vantagem e (6) no cumprimento do Texto Constitucional. (CLARK; COSTA, 2015, p. 107-108).
}

Apesar do que o entendimento comum pode indicar, ao relacionar o termo planejamento com as economias planificadas dos países socialistas, o planejamento se vincula ao regime político e à ideologia determinada pelo texto Constitucional. Caberá a Constituição definir a ideologia adotada pela nação para que, então, o Direito Econômico possa atuar fornecendo os instrumentos adequados, em especial, os Planos enquanto instrumentos constituidores das políticas públicas, inclusive as econômicas, conforme a ideologia constitucionalmente adotada (SOUZA, 2017, p. 28-29).

O planejamento obedece ao tipo de regime político a que se aplica, o que mais uma vez confirma a nossa afirmativa de que o Direito Econômico não está comprometido

Rev. de Direito, Economia e Desenvolvimento Sustentável| e-ISSN: 2526-0057| Maranhão | v. 3 | n. 2 | p. 61 - 81 | Jul/Dez. 2017. 
especificamente com nenhum deles, mas tão somente a disciplinar a Política econômica correspondente à ideologia adotada. (SOUZA, 2005, p. 376).

Dentro deste contexto, o João Bosco Leopoldino da Fonseca (2010, p. 255) adverte que a racionalidade do controle das políticas econômicas surge tanto no contexto das economias de mercado como nas economias planificadas e centralizadas soviéticas.

Não há que se confundir o planejamento com o plano. O primeiro, conforme já dito anteriormente, constitui o "ato de planejar", que consiste na racionalização dos meios disponíveis (SOUZA, 2017, p. 372 ) ou na reunião de esforços, políticos, econômicos e jurídicos (CLARK; COSTA, 2015, p. 107 para se atingir os efeitos mais favoráveis ou maior vantagem, conforme determinada pela Constituição. O Plano, por sua vez, é a peça técnica decorrente do planejamento, que será convertida em Lei, tratada como a Lei do Plano, para que possa ser posta em execução (SOUZA, 20017, p. 373). É importante ressaltar que a Constituição da República fixa diversas leis planejadoras, entre elas o Plano Plurianual (art. 165, I da CR).

Enquanto vigente, a Lei do Plano é "o diploma definidor da Política Econômica que o país adota" (SOUZA, 2003, p. 383). A execução da Lei do Plano será efetivada por meio dos instrumentos jurídicos colocados à disposição da Administração Pública, seja atos administrativos de natureza normativa, seja atos administrativos concretos, que criem ou reconheçam direitos dos particulares ou que modifiquem a estrutura daquela, prevendo a criação de conselhos, comissões, grupos de trabalhos, forças-tarefas, subsídios públicos, etc.

A vivência contemporânea em regime democrático, cláusula constitucional não sujeita a reforma, determina que o processo de elaboração da Lei do Plano deverá também pautado na participação social. Nesse aspecto, a peça técnica deverá ser encaminhada à deliberação e aprovação pelo Legislativo correspondente - isso pois, não se afasta que o plano poderá ter âmbito nacional, regional ou local. Ao Legislativo correspondente garante-se ampla discussão sobre a Lei do Plano e a possibilidade de sua alteração dentro do processo legislativo, sem o qual o processo de concepção dela não poderá ser tratado como democrático.

\subsection{O Plano Plurianual da União - 2016-2019}

O Plano Plurianual da União (PPA) foi instituído pela Lei Federal nº. 13.249/2016. De acordo com a Lei é instrumento de planejamento governamental que define diretrizes, objetivos 
e metas da administração pública federal para as despesas de capital e outras delas decorrentes e para as relativas aos programas de duração continuada, com o propósito de viabilizar a implementação e a gestão das políticas públicas de 2016 a 2019. Ademais é o planejamento federal para 04 anos, ou seja, a curto prazo.

Entre as diretrizes indicadas pela dita Lei, encontram-se "o desenvolvimento sustentável orientado pela inclusão social", "A melhoria contínua da qualidade dos serviços públicos", "A participação social como direito do cidadão" e "A garantia do equilíbrio das contas públicas". O período atravessado pela nação e pelo mundo, com forte discussão sobre o controle e equilíbrio dos gastos públicos, influenciou a definição de suas diretrizes. Aliás, tema recorrente das leis planejadoras estatais brasileiras.

Ainda que extremamente relevante, a proteção adequada das unidades de conservação, com a previsão de significativo dispêndio financeiro para sua implantação, parece não se alinhar integralmente às diretrizes gerais do PPA. Contudo, por se tratar de dever constitucional, o Estado não pode se furtar de executar as medidas de implantação dos espaços protegidos que ele mesmo criou.

Dessa forma, mesmo que timidamente, o PPA destaca alguns programas e ações voltadas a efetivação dos espaços territoriais especialmente protegidos.

As unidades de conservação são tratadas pelo Programa 2078, do Anexo I, da Lei Federal no 13.249/2016, com o título de "Conservação e Uso Sustentável da Biodiversidade". Utilizando-se como data de referência em 18/06/2015, o Programa relaciona como indicador o percentual de 19,63 de áreas regularizadas em unidades de conservação federais, o percentual 82,18 de unidades de conservação federais com Conselhos Gestores formados, o percentual de 48,44 unidades de conservação federais com Plano de Manejo e o percentual de 24,31 unidades de conservação federais demarcadas.

Os índices apontados pelo Programa indicam que o planejamento da União caminha no sentido de dotar as unidades de conservação com o mínimo legal necessário objetiva a integral implantação das áreas protegidas, digo: o domínio público das propriedades inseridas no seu interior, a concretização dos Conselhos Gestores e dos Planos de Manejos.

As ações voltadas ao fortalecimento do Sistema Nacional das Unidades de Conservação estão descritas no Objetivo 1070 do Plano Plurianual 2016-2019, englobando a consolidação das unidades de conservação federais. 
As metas propostas pelo Governo Federal são: a) aumentar de $40 \%$ para $60 \%$ a área das Unidades de Conservação avaliadas e cumprindo com seus objetivos de criação, conforme metodologia de monitoramento de efetividade de gestão; b) ampliar de 155 para 215 Unidades de Conservação Federais dotadas com Planos de Manejo; c) aumentar de 265 para 283 Unidades de Conservação Federais com conselhos gestores criados; d) ampliar a regularização fundiária de 12,9 milhões de hectares para 17,9 milhões de hectares nas Unidades de Conservação Federais.

As metas propostas pelo Governo Federal e aprovadas pelo Congresso Nacional estão definidas, são mensuráveis e permitem ações adequadas para a efetivação das unidades de conservação federais. Entretanto, estão muito aquém do limite exigido para se considerar as unidades de conservação adequadamente implantadas, isto é, cumprindo as determinações da Lei do SNUC e, por consequência, atendendo a obrigação imposta pela Constituição de 1988.

Para se comparar os desafios do Poder Público com as metas previstas no Plano Plurianual 2016-2019, deve-se considerar que o universo de unidades de conservação criadas pela União é de 960 unidades. Desse total, deve-se desconsiderar a quantidade de 634 Reservas Particulares do Patrimônio Natural que são unidades de conservação privadas e de gestão do particular responsável pela sua criação. Isso resulta no total de 326 unidades de gestão pública, conforme indicam o próprio Cadastro Nacional de Unidades de Conservação ${ }^{7}$.

A meta traçada é constituir de Plano de Manejo até 2019, 215 unidades federais e de Conselhos Gestores, 283 unidades, do total de 326 unidades, cuja responsabilidade de gestão é da União. Isso representa um déficit, em 2019, de 111 unidades que ainda não terão Plano de Manejo e 43 unidades que não terão Conselho Gestor, mantida o número atual de unidades.

Quando se trata de regularização fundiária a situação é ainda mais alarmante. Considerando apenas as unidades de conservação que exijam legalmente o domínio público, a União precisaria regularizar a área de 68.430.100 hectares, ainda fora do planejamento estatal. A meta buscada em 2019 é de 17.900.000 hectares, o que corresponde a um déficit de mais de 50 milhões de hectares. O desafio atual do Governo Federal é a regularização fundiária de 55,73 milhões de hectares, área equiparável ao Estado da Bahia.

\footnotetext{
${ }^{7}$ disponível em: http://www.mma.gov.br/images/arquivo/80112/CNUC_Agosto\%20-\%20Categorias_copy.pdf , Acessado em 22/01/2017.
} 
Apesar do esforço do Poder Público, a nação ainda está longe dar efetividade e ter sucesso na gestão desses espaços protegidos.

\section{CONSIDERAÇÕES FINAIS}

O Planejamento consiste na adoção de atos pelo Poder Público de forma a racionalizar o uso dos recursos econômicos e instrumentos jurídicos para se atender os desígnios da Constituição, em conformidade com a ideologia adotada. O processo constitucional de sua consecução terá como ponto de partida a elaboração da peça técnica. Em respeito ao processo democrático, deverá ser discutida e aprovada pelo Legislativo resultando em uma lei planejadora, mas sempre com participação de segmentos sociais envolvidos.

A Constituição da República impõe ao Poder Público o dever de defender o e preservar o direito ao meio ambiente ecologicamente equilibrado para as presentes e futuras gerações. Para tanto incumbe a ele a definição de espaços e seus componentes a serem especialmente protegidos. Tal incumbência não se encerra com a criação de unidades de conservação, espaços territoriais especialmente protegidos em sentido estrito. O integral cumprimento do dever constitucional significa a efetiva implantação das unidades, de forma a permitir concretude ao desígnio constitucional.

Para tanto, o planejamento deve ser centrado na execução dessa implantação efetiva. Isso significa, no mínimo, o atendimento aos requisitos impostos pela Lei $n^{\circ}$ 9.985/2000, que considera para a implantação: (a) o domínio público, nas modalidades de unidades de conservação específicas; (b) a existência de um Plano de Manejo, e; (c) a constituição de Conselho Gestor para todas as unidades.

O Plano Plurianual da União, Lei Federal $n^{\circ}$. 13.249/2016, determina metas que buscam atender essa efetiva implantação. As metas propostas pelo Governo Federal e aprovadas pelo Congresso Nacional estão bem definidas, são mensuráveis e permitem ações adequadas para a efetivação das unidades de conservação federais.

O principal desafio, entretanto, se concentra no atendimento integral de todas as unidades de conservação criadas pelo Poder Público Federal. Em 2019, atendido integralmente o Plano Plurianual, a União ainda terá um déficit significativo de unidades de conservação federal sem Planos de Manejo e sem Conselhos instituídos. O quadro mais grave se refere a

Rev. de Direito, Economia e Desenvolvimento Sustentável| e-ISSN: 2526-0057| Maranhão | v. 3 | n. 2 | p. 61 - 81 | Jul/Dez. 2017. 
necessidade de domínio público, pois, caso alcançada a meta proposta, representará que apenas $26,15 \%$ de unidades existentes atenderiam o que determina a Lei do SNUC.

\section{REFERÊNCIAS}

ANTUNES, Paulo de Bessa. Direito Ambiental. 10ª ed. Rio de Janeiro: Lumen Juris, 2007. 564-565.

AZEVEDO, Marcelo; MOREIRA, Luísa Santos Sette Câmara. A Conservação de ecossistemas por meio de áreas de proteção: A criação da Lei do SNUC e as perspectivas para o futuro. In: FREIRE, William; MATTOS, Tiago. (coord.) Aspectos controvertidos do Direito Minerário e Ambiental. Belo Horizonte: Jurídica, 2013.

BENJAMIM, Antônio Herman. O Regime Jurídico Brasileiro de Unidades de Conservação. Revista de Direito Ambiental. a. 06, v. 21, jan.-mar., 2001 p. 27-56.

BENJAMIN, Antônio Herman. Introdução à lei do sistema nacional de unidades de conservação. In: BENJAMIN, Antônio Herman. (coord.) Direito ambiental das áreas protegidas - $O$ regime jurídico das unidades de conservação. Rio de Janeiro: Forense Universitária, 2001, p. 276-316.

BRASIL. Constituição (1988). Constituição da República Federativa do Brasil. Brasília: Senado, 1988.

BRASIL. Lei n. 9.985, de 18 de julho de 2000. Regulamenta o art. 225, § 1o, incisos I, II, III e VII da Constituição Federal, institui o Sistema Nacional de Unidades de Conservação da Natureza e dá outras providências. Diário Oficial da União, Brasília, 19 jul. 2000.

BRASIL. Lei n. 13.249, de 13 de janeiro de 2016. Institui o Plano Plurianual da União para o período de 2016 a 2019. Diário Oficial da União, Brasília, 14 jan. 2016.

BRASIL. Supremo Tribunal Federal. Ação Direta de Inconstitucionalidade n. 3.378. Relator do acórdão: Carlos Ayres Britto. Diário de Justiça Eletrônico, Brasília, 20 jun. 2008. Disponível em http://redir.stf.jus.br/paginadorpub/paginador.jsp?docTP=AC\&docID=534983. Acesso em: 10 jan. 2017.

BRASIL. Supremo Tribunal Federal. Mandado de Segurança n. 24.184. Relatora: Ellen Gracie. Diário de Justiça Eletrônico, Brasília, 27 fev. 2004. Disponível em http://www.stf.jus.br/portal/jurisprudencia/visualizarEmenta.asp?s1=000014265\&base=baseA cordaos. Acesso em: 15 jan. 2017.

BRASIL. Tribunal Regional Federal da $1^{\mathrm{o}}$ Região. Agravo de Instrumento n. 2006.01.00.015900-0. Relatora: Maria Isabel Gallotti Rodrigues. Diário de Justiça Eletrônico, Brasília, 29 jan. 2007. Disponível em http://arquivo.trf1.jus.br/PesquisaMenuArquivo.asp?p1= $200601000159000 \& \mathrm{pA}=200601000159000 \& \mathrm{pN}=164703420064010000$. Acesso em: 15 jan. 2017.

Rev. de Direito, Economia e Desenvolvimento Sustentável| e-ISSN: 2526-0057| Maranhão | v. 3 | n. 2 | p. 61 - 81 | Jul/Dez. 2017. 
CLARK, Giovani; COSTA, Gustavo Vidigal. O Desplanejamento Estatal: o exemplo da Copa do Mundo de 2014 no Brasil. In: CLARK, Giovani; CORRÊA, Leonardo Alves; NASCIMENTO, Samuel Pontes. Direito Econômico em Debate. São Paulo: LTR, 2015, p. 96-128.

COSTA NETO, Nicolao Dino de Castro e. Proteção Jurídica do Meio Ambiente. I Florestas. Belo Horizonte: Del Rey, 2003, p. 203.

FIGUEREIDO, Guilherme José Purvin de; LEUZINGER, Márcia Dieguez. Desapropriações ambientais na Lei n. 9.985/2000. In: BENJAMIN, Antônio Herman. (coord.) Direito ambiental das áreas protegidas - $O$ regime jurídico das unidades de conservação. Rio de Janeiro: Forense Universitária, 2001, p. 465-490.

FIORILLO, Celso Antônio Pacheco. RODRIGUES, Marcelo Abelha. Manual de Direito Ambiental e Legislação Aplicável. 2a ed. São Paulo: Max Limonad, 1999, p. 195.

FONSECA, João Bosco Leopoldino da. Direito Econômico. $6^{\text {a }}$ ed. Rio de Janeiro: Forense, 2010.

MACHADO, Paulo Affonso Leme. Direito Ambiental Brasileiro. 24 $4^{\mathrm{a}}$ ed. São Paulo: Malheiros, 2016.

MILARÉ, Édis. Direito do Ambiente. 8ª ed. São Paulo: Revista dos Tribunais, 2013.

SOUZA, Washington Albino Peluso de. Primeiras Linhas de Direito Econômico. $6^{\mathrm{a}}$ ed. $2^{\mathrm{a}}$ Tiragem. São Paulo: LTR, 2017. 